\title{
SOCIAL AND ECONOMIC CONDITIONS AND THE INCIDENCE OF RHEUMATIC HEART DISEASE
}

BY

\section{G. H. DANIEL}

It has not been the custom of this Journal to review papers of cardiological interest. However this paper, published in the Journal of the Royal Statistical Society (1942) 105, 197, seems to justify making an exception, as it is pertinent to the preceding report and may not have been easily available to all who are interested.

That rheumatic fever and mitral stenosis are more common among the poor than the rich is accepted teaching, supported by much experience and statistical evidence. This, however, fails to show if the difference is due to the effect of income on diet, or on housing, or on other conditions of the environment-material or mental-or might even be explained by hereditary factors. A much more detailed statistical analysis would be needed to isolate these facts.

The Medical Research Council's Report of 1927 sought to evaluate the effects of social and economic conditions by comparing the living conditions of 721 families with children attending hospital for rheumatism with those of 200 families with children attending hospital for non-rheumatic diseases. Of this Daniel says: "It is quite possible that their diseases as well as those of the rheumatic families were related to adverse social and economic circumstances. In that case, comparison could not be expected to reveal the importance of those conditions. The rheumatic families should be compared with the total population."

In 1937 the University of Bristol with the Colston Research Society investigated the circumstances of a random sample (one family in twenty-two) of the Bristol working class population. With the data available the opportunity was taken of comparing the incidence of rheumatism with some of the other social and economic factors; rheumatic heart disease was taken as the significant evidence because this was a more precise criterion.

The number of rheumatic families in each class was divided by the number of families from the sample of the total working-class population in the same class and, to facilitate comparison of incidence between the classes, the result was expressed as a percentage of the proportion between all 341 rheumatic families and 1424 families in the total population sample. This gave for each class the incidence of the disease as a percentage of the average incidence among the entire population studied.

The Bristol data thus yield the following information:

(a) Incidence of rheumatic heart disease in each group of working-class families as a percentage of the average incidence for all Bristol working-class families. This will be taken as the dependent variable (Y) and for the sake of brevity it will be referred to as the "incidence."

(b) Income available for expenditure on food, clothes, and fuel as a percentage of minimum needs. This independent variable (X1) will be referred to simply as the " net income." It is not, of course, the total family income that is likely to affect susceptibility to disease, as much as the income relative to the needs of the family.

(c) Number of rooms per person (X2).

(d) Use of a basement room, receipt of meals or milk at school, and membership of a doctor's club.

The conclusions reached about $(b)$ and $(c)$ are shown in Tables I and II. 
TABLE I

Incidence of Rheumatic Heart Disease in Relation to Net Income

\begin{tabular}{|c|c|c|c|c|c|c|}
\hline \multicolumn{3}{|c|}{$\begin{array}{l}\text { Net income (as a } \\
\text { percentage of minimum } \\
\text { needs) }\end{array}$} & \multirow{2}{*}{$\begin{array}{c}\begin{array}{c}\text { Families with } \\
\text { rheumatic heart } \\
\text { disease }\end{array} \\
77 \\
54 \\
51 \\
33 \\
37 \\
31 \\
17 \\
41\end{array}$} & \multirow{2}{*}{$\begin{array}{c}\begin{array}{c}\text { Families in sample } \\
\text { of total working- } \\
\text { class population }\end{array} \\
232 \\
152 \\
191 \\
192 \\
192 \\
149 \\
93 \\
223\end{array}$} & \multirow{2}{*}{$\begin{array}{c}\begin{array}{c}\text { Incidence of } \\
\text { rheumatic disease } \\
\text { (as a percentage of } \\
\text { average incidence }\end{array} \\
139 \\
148 \\
112 \\
72 \\
81 \\
87 \\
76 \\
77\end{array}$} & \multirow{2}{*}{$\begin{array}{c}\text { Expected incidence* } \\
142 \\
122 \\
108 \\
97 \\
88 \\
81 \\
75 \\
70\end{array}$} \\
\hline $\begin{array}{l}\text { Under } 100 \\
100-120 \ldots \\
120-140 \ldots \\
140-160 \ldots \\
160-180 \ldots \\
180-200 \ldots \\
200-220 \ldots \\
220 \text { and over }\end{array}$ & $\begin{array}{l}\cdots \\
\cdots \\
\cdots \\
\cdots \\
\cdots \\
\cdots \\
\cdots\end{array}$ & $\begin{array}{l}\cdots \\
\cdots \\
\cdots \\
\cdots \\
\cdots \\
\cdots\end{array}$ & & & & \\
\hline Tota & . & $\cdots$ & 341 & 1424 & - & -- \\
\hline
\end{tabular}

* Estimated from $Y=4291 \quad X_{1}^{-0.757}$

TABLE II

Incidence of Rheumatic Heart Disease in Relation to the Number of Rooms Per Person

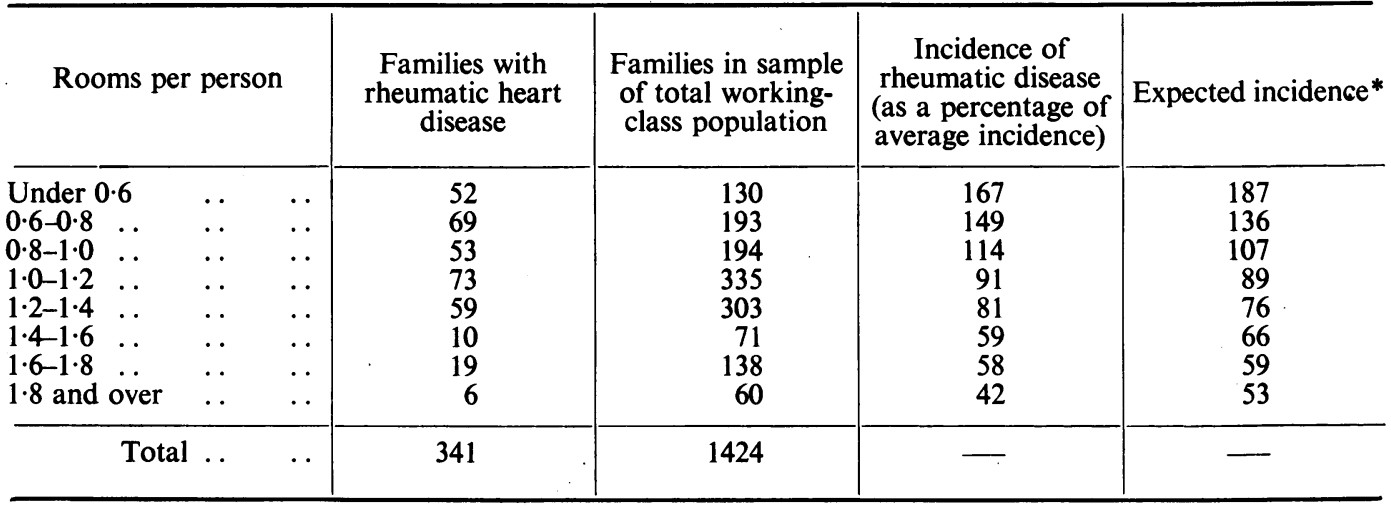

* Estimated from $\mathrm{Y}=95 \cdot 1 \mathrm{X}_{2}^{-1 \cdot 037}$.

The information gathered about the living conditions of the Bristol working-class population allows the following conclusions to be drawn.

(a) Differences in incidence of rheumatic heart disease between sections of this population were associated with differences in the family income available after paying for rent, rates, travelling, and other fixed items, expressed as a percentage of minimum needs.

(b) Considerable differences in incidence corresponded closely with the variation in the number of rooms used by each family divided by the number of persons in the family.

(c) Families which belonged to doctors' clubs suffered less from the disease than did the remainder of the population.

(d) There is an indication, though the results are not statistically significant, that families which lived or slept in basement rooms included more cases of the disease than other families.

(e) Each one of these relations was true independently of the others.

To what extent these findings based on the Bristol 1937 experience apply to the population of the whole country is unknown. But Bristol is a large town, and there is no apparent reason why the relations found should be confined to it.

This short summary and extract will give some idea of the care with which conclusions have been reached, and may refer some who are interested to the original paper. 